\section{Replacing and relocating percutaneous endoscopic gastrostomy tube without esophagogastroscopy}

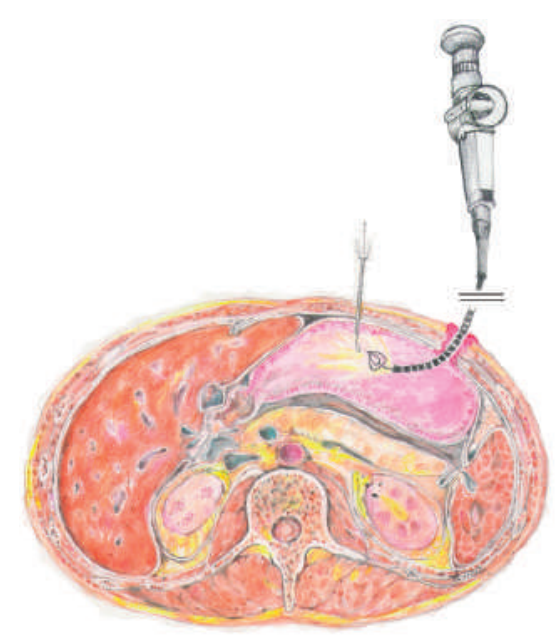

Figure 1 After the PEG tube was gently pulled out by external traction from the infected gastrostomy site, a standard-size esophagogastroscope was inserted via the same gastrocutaneous tract to perform gastroscopy. A new site was selected well away from the infected previous stoma and a normal pull-back PEG was carried out, except that the string was pulled out and the new PEG feeding tube was inserted through the old gastrostomy opening. A "second-look" gastroscopy was also carried out easily, causing no discomfort for the patient.

Percutaneous endoscopic gastrostomy (PEG) [1] is widely used for the enteral nutrition of patients with head and neck cancer. While very safe and well tolerated, it is not without its complications. Long-term use of PEG can lead to complications requiring replacement of the gastrostomy tube and relocation of the feeding tube to a new site $[2,3]$. Replacing the

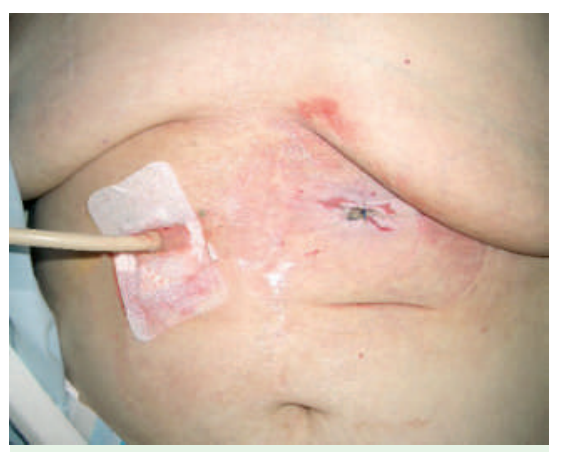

Figure 2 PEG feeding tube positioned well away from the infected previous gastrostomy site.

feeding tube is an easy, straightforward procedure if done shortly after the removal of the old one, while relocating it to a new site requires repeat esophagogastroscopy. However, standard peroral or transnasal introduction of the esophagogastroscope is not always possible in patients with head and neck cancers. Narrowness of the pharyngeal space in consequence of major head and neck surgery and radiotherapy can impede peroral feeding, which makes the patient dependent on feeding by gastrostomy tube for life. Replacing and relocating the gastrostomy tube for such patients to a new site in the case of any complication cannot be done endoscopically in the usual way. The technique illustrated in $\bullet$ Figure $\mathbf{1}$ and $\mathbf{2}$ allows endoscopically controlled replacement and relocation of the PEG feeding tube without the performance of a traditional peroral esophagogastroscopy.
No general anesthesia was required. Both the gastroscope and the PEG feeding tube was passed through the former gastrostomy opening without any difficulty. I recommend the described technique of replacing and relocating the PEG feeding tube for patients with head and neck cancer, if peroral esophagogastroscopy cannot be carried out.

Endoscopy_UCTN_Code_TTT_1AO_2AK

\section{Lujber}

Department of Oto-Rhino-Laryngology, Head and Neck Surgery, Pécs University, Medical School, Pécs, Hungary

\section{References}

1 Gauderer MW, Ponsky JL, Izant RJ. Gastrostomy without laparotomy: a percutaneous endoscopic technique. J Pediatr Surg 1980; 15: $872-875$

2 Bumpers HL, Collure DW, Best IM et al. Unusual complications of long-term percutaneous gastrostomy tubes. J Gastrointest Surg 2003; 7: 917-920

3 Anwander T, Berge S, Appel T et al. Percutaneous endoscopic gastrostomy for longterm feeding of patients with oropharyngeal tumors. Nutr Cancer 2004; 50: 40-45

Bibliography

DOI $10.1055 / s-2007-966567$

Endoscopy 2007; 39: E174

(c) Georg Thieme Verlag KG Stuttgart · New York . ISSN 0013-726X

\section{Corresponding author}

\section{Lujber, MD, PhD}

Department of Oto-Rhino-Laryngology,

Head and Neck Surgery

Pécs University Medical School

Munkácsy M. str. 2

7621 Pécs

Hungary

Fax: +36-72-228119

Lujber@yahoo.com 